\title{
Water stress affects Tomicus destruens host pine preference and performance during the shoot feeding phase
}

\author{
Manuela Branco $^{1 *}$, João Santos PEREIRA ${ }^{1}$, Eduardo MATEus $^{2}$, Catarina TAVAres ${ }^{1}$, Maria Rosa PAIVA $^{1,2}$ \\ ${ }^{1}$ Centro de Estudos Florestais (CEF), Instituto Superior de Agronomia (ISA), Technical University of Lisbon (UTL), 1349-017 Lisbon, PT, Portugal \\ ${ }^{2}$ CENSE, Dep de ciências e Engenharia do Ambiente (DCEA), Faculdade de Ciências e Tecnologia, FCT, Universidade Nova de Lisboa, \\ 2829-516 Caparica, PT, Portugal
}

(Received 27 July 2009; accepted 1 December 2009)

Keywords:

pine shoot beetle /

Pinus pinaster /

drought stress /

VOCs /

host selection

\begin{abstract}
- The effect of water stress on host selection and performance during the shoot feeding phase, by the Mediterranean pine shoot beetle Tomicus destruens, was studied.

- Young potted Pinus pinaster plants were subjected to two water supply regimes: (i) well watered; (ii) $4-5$ months of moderate drought stress. Plant volatile organic compound (VOCs) emissions were collected by SPME and analysed by GC/MS.

- In tests with paired plants, the number of holes and tunnels excavated by beetles in well watered pines was significantly larger than in stressed plants, whereas in no-choice tests no differences occurred.

- Beetle survival was significantly higher on well watered, than on stressed pines ( $p=0.006$ ), while fat contents also increased ( $p=0.09$ ).

- Plants could be assigned to treatments based on VOCs emissions, stressed pines emitting more myrcene and less $\beta$-pinene than well watered ones.

- It is concluded that during the shoot feeding phase, T. destruens preferentially attacks non-stressed plants, in detriment of stressed ones, upon which a higher fitness is attained.

- The role of pines VOCs emissions under moderate drought stress, in the host selection and colonization process by the pine shoot beetle, is discussed.
\end{abstract}

\section{INTRODUCTION}

Most climate change scenarios for Mediterranean regions suggest the future occurrence of longer dry seasons and higher temperatures than present. Under such circumstances, forest trees will more frequently become prone to moderate water stress, which will affect their primary and secondary metabolism and in consequence, plant-herbivore interactions.

Bark beetles are important herbivores in pine forests (e.g. Grégoire and Evans, 2004), causing damage generally associated with trunk attack. Adults bore entering holes through the bark and excavate galleries where eggs are laid. Larval feeding may ultimately lead to tree death, due to sap phloem disruption.

Additionally for some scolytids, such as those in the genus Tomicus, a shoot feeding phase in the adult stage is indispensable for the completion of sexual maturation and successful reproduction (e.g. Fernandez Fernandéz et al., 1999).

Tunnels are excavated inside the shoots by the beetles, but the damage caused is frequently inconspicuous and considered of minor importance. Yet, at high population levels, intense defoliation may result from shoot fall, as well as crown reduction, tree growth loss and an increased tree susceptibility

\footnotetext{
*Corresponding author: mrbranco@isa.utl.pt
}

to subsequent trunk attacks (Långström et al., 2002; Lieutier et al., 2003).

Crops with valuable crowns are particularly vulnerable, such as Christmas trees in North America, to which severe economic losses were inflicted, after the introduction in 1993, of Tomicus piniperda L. (Haack et al., 2001). In Portugal, pinion production may become compromised after intense attacks of Tomicus destruens Wollaston to Pinus pinea L. (Branco, pers. observ.).

Bark beetles damage to woody plants has been associated with drought stress (Lorio et al., 1995), as a result of reduced oleorosin flows and other defence mechanisms. Additionally, higher levels of nitrogen and soluble sugars in the phloem might contribute to improve scolytid performance (Mattson and Haack, 1987). Susceptibility to herbivory depends both on the plants content in secondary metabolites, which have a chemical defensive role, as well as on its nutritional value, as determined by primary metabolism. Plant resistance is further affected by the levels of constitutive and inducible defences, the latter appearing after herbivore attack (Lombardero et al., 2000).

Insect performance may increase, decreased or remain unaffected in response to drought stress, while varying among 
insect feeding-guilds due to different evolutionary and physiological mechanisms (review by Koricheva et al., 1998).

Several studies conducted on host selection and performance regarding scolytid trunk attack, generally agree that weakened trees attract more beetles than vigorous ones (Schröeder, 1987). However, for trees under moderate drought stress, a decreased susceptibility to colonization by bark beetles has also been reported (Lombardero et al., 2000).

While previous studies focused on the effect of water stress upon trunk attack, substantial knowledge on insect host preferences and performance during the shoot feeding phase is still lacking. Understanding the interactions between pines and Tomicus spp., during the shoot feeding phase, will contribute to model tree attack by other beetles, having similar ecological characteristics.

Trunk colonization by Tomicus spp. is mediated by host chemical signals, in particular monoterpenes (e.g. Vité et al., 1986). Nevertheless, mechanisms of host selection during shoot attack remain to be decoded, although some probable chemical mediators have been identified (Almquist et al., 2006; Faccoli et al., 2008).

T. destruens is an economically important pine pest in the Mediterranean (e.g., Faccoli et al., 2008; Mendel, 1987). In Portugal, $T$. destruens preferentially colonizes maritime pine Pinus pinaster Ait., being distributed at lower latitudes than $T$. piniperda, although both species sometimes occur in sympatry (Vasconcelos et al., 2006). In the studied area, shoot feeding takes place in the spring/summer and reproduction in the autumn/winter, whereas in northern Italy shoot feeding was observed to occur in the summer/fall and reproduction in the spring, following a phenology similar to that of T. piniperda (Faccoli et al., 2005). In all cases however, part of the shoot feeding takes place in the summer, which is a critical period for water stress in Mediterranean regions.

The objectives of this study were: (i) Using T. destruens $P$. pinaster as a model interaction, to determine host preferences and adult performance in the shoot feeding phase, under conditions of moderate drought stress; (ii) To analyze the composition of the VOCs emitted by drought stressed and non stressed pine plants; (iii) To compare, using discriminant analysis, the VOC emissions from both tree groups.

\section{MATERIALS AND METHODS}

\subsection{Plant material and treatments}

Experiments took place over three consecutive seasons: 20052006, 2006-2007 and 2007-2008, using plants of $P$. pinaster three years old, about $1.3 \mathrm{~m}$ high, which were subjected to two different water regimes: (i) well watered throughout; (ii) four to five months of drought stress.

Plants were placed in pots (volume $37 \mathrm{~L}$, height $35 \mathrm{~cm}$ ), filled with a commercial substrate composed of turf and vermiculite $(2: 1 \mathrm{v} / \mathrm{v})$. A liquid fertilizer Complesal ( $\mathrm{N}: \mathrm{P}: \mathrm{K}=12: 4: 6$ and micronutrients) was applied to all plants at the beginning of the experiment. Due to destructive sampling, in each season new plants were used, being allocated to treatments, in equal numbers.
A moderate water stress was imposed during the summer through the incomplete replacement of water transpired and evaporated from the soil, which was estimated by weighting the tree pots weekly, or quarterly. Plants subjected to drought stress were watered once, or twice per week, depending on the weight loss estimate assigned to transpiration. A group of plants was kept well watered throughout the whole season, that is watered to soil field capacity, once or twice per week. In 2005, a period of four months drought stress was applied, from September till the end of December, whereas in 2006 and 2007 drought stress was applied from July till December. Still, since in August air temperatures frequently reached $40{ }^{\circ} \mathrm{C}$ and increased transpiration was observed, plants were concomitantly watered more regularly, to avoid excessive drought stress and death.

Predawn needle water potential (needle $\psi$ ) was measured with a Scholander pressure chamber in one year old needles. Plant water condition was monitored in four to eight pine plants sampled from each group, at the middle of the treatment period. Final predawn needle $\psi$ was measured each year in plants sampled randomly from each treatment group, c.a. 5 days after the last watering event $(n=11,36$ and 71 , respectively in 2005, 2006 and 2007), to estimate differences between group treatments, just before the beginning of the trials.

\subsection{Bark beetles}

Bark beetles were obtained by exposing trap-trees in $P$. pinaster stands, from mid September to the end of October. Within one month after beetle attack was observed, trap-trees were cut into $30-40 \mathrm{~cm}$ $\operatorname{logs}$ and transported to the laboratory, where they were kept in net bags. Callow adults emerged at room temperature and were collected daily. Beetles were kept at $8{ }^{\circ} \mathrm{C}$, starved for up to 2 days prior to being used in the trials. Emergences started in mid/late December and extended until February /March.

\subsection{Host preference and performance}

Two types of trials were conducted, single tree, i.e. no-choice tests, and paired trees, i.e. two-choice tests. In no-choice tests, potted pine trees were placed individually inside a net bag chamber with $1 \mathrm{~mm}$ mesh. Two active $T$. destruens beetles, emerged within the previous 24 to $48 \mathrm{~h}$, were inserted in each chamber, in the morning. No-choice tests were conducted in January-February of 2006 and 2007, using half of the trees for each treatment (Tab. I). Every other day, trees were scrutinized for signs of shoot attack, such as dust and/or boring holes. After colonization was observed, plants were kept inside the chamber for 15 further days, in 2006, and for 28 days in 2007, allowing the beetles to feed. Pine plants and pots were then examined, all shoots being dissected and the number of entry holes, successful tunnels, length of tunnels and number of dead and live beetles at the entry holes, or inside the shoots recorded. Live beetles were further kept for fat content analysis. The number of entry holes and of tunnels excavated were considered as indicators of insect preferences, whereas length of tunnels, mortality and fat content provided information on insect performance.

In paired-choice tests, one pine from each treatment was placed in a net chamber mounted on a $1.3 \mathrm{~m} \times 1.0 \mathrm{~m} \times 0.5 \mathrm{~m}$ wooden frame. Thirteen tests were performed between December 2006 and February 2007, and 53 between January and March 2008 (Tab. I). A single beetle was inserted in each chamber. Plants were checked daily and 
Table I. Number of plants used in the host preference trials. In each season, half of the plants were allocated to each treatment: drought stressed or well watered plants.

\begin{tabular}{lcc}
\hline Season & No-choice tests & Two-choice tests \\
\hline $2005-2006$ & 12 & \\
& 12 & 13 \\
$2006-2007$ & 20 & 13 \\
& 20 & 53 \\
$2007-2008$ & & 53 \\
\hline
\end{tabular}

whenever after two to three days later no signs of attack were evident, a new beetle was inserted into the chamber. After colonization, i.e. when a boring hole was observed, the attacked tree was removed and kept isolated in a net bag, allowing the beetle to feed. Plants not attacked were still kept in the chamber, for future examination. The feeding period was determined to last for $28 \mathrm{~d}$, in 2007, and 42 days in 2008. After this period, both plants were carefully examined, shoots dissected, beetles removed and data recorded similarly as for the nochoice tests.

\subsection{Fat content}

Live beetles removed from the tunnels of both experiments were kept frozen at $-4{ }^{\circ} \mathrm{C}$, for fat content analysis by the Anderbrant method (1988). The beetles were first dried at $60{ }^{\circ} \mathrm{C}$ for $24 \mathrm{~h}$ and weighted individually to the nearest $0.1 \mathrm{mg}$, with precision scales. Lipids were extracted twice from the dried beetles, each time with $1 \mathrm{~mL}$ petroleum ether during $24 \mathrm{~h}$, at $38{ }^{\circ} \mathrm{C}$. Beetles were again dried at $60{ }^{\circ} \mathrm{C}$ for $24 \mathrm{~h}$ and weighted. Fat content was estimated as the difference between the two dry weight measurements and expressed as percentage of the initial weight. Fat content was determined in three beetles from drought stressed plants and in nine from well watered plants in 2006, and in nine beetles from drought stressed and in 15 from well watered plants, in 2007. In 2008 fat contents were not determined due to a conservation mishap.

\subsection{Volatile emissions}

The volatile compounds emitted were sampled by enclosing the tree canopy in a recycled demijohn with an open bottom, for one hour at room conditions. This procedure allowed for volatile emissions to take place, while the analysis could be performed at constant volume, contaminant free. Volatiles were collected by SPME (solid phase microextraction) during one hour, using a $100 \mu \mathrm{m}$ polydimethylsiloxane (PDMS) fiber and injected at the chromatographic systems by thermal desorption at the gas chromatograph injector body. The manual SPME holder, the samples and the collection vessels were fixed to a bench mounted support stand, with $1.5 \mathrm{~m}$ aluminum rods, using stainless steel clamps. The demijohns were submitted to blank and control analysis, i.e. before and after sampling, no artifacts or volatile carryover/ memory effects having been found.

Volatiles were analyzed by GC-FID, using a HP 5890 A gas chromatograph (Hewlett Packard, USA) equipped with flame ionization detection (GC-FID). Identifications were confirmed by GC/MS (gas chromatography - mass spectrometry) using a Finnigan TRACE MS
(ThermoQuest, Austin, USA) and an Agilent $6890 \mathrm{~N}$ gas chromatograph, coupled to a GCT mass spectrometer detector (Manchester, UK) equipped with a time-of-flight (TOF) mass analyzer.

Two capillary columns, coated with a 5\%-Phenyl 95\%Dimethylpolysiloxane phase, were used to perform the volatiles separation. A ZB-5 ms $30 \mathrm{~m} \times 0.25 \mathrm{~mm}$ i.d.; $0.25 \mu \mathrm{m}$ (Phenomenex, Torrance, USA) was used for GC/MS analysis and a DB-5 $30 \mathrm{~m} \times$ $0.32 \mathrm{~mm}$ i.d.; $1.00 \mu \mathrm{m}$ (J\&W Scientific, Folsom, CA, USA) for GCFID analysis. The oven temperature programme begun at $50{ }^{\circ} \mathrm{C}$ for one minute, followed by a ramp of $4{ }^{\circ} \mathrm{C} \cdot \mathrm{min}^{-1}$, until a temperature of $125^{\circ} \mathrm{C}$ was reached, followed by another ramp of $6{ }^{\circ} \mathrm{C} \cdot \mathrm{min}^{-1}$, up to $250{ }^{\circ} \mathrm{C}$. Helium was used as carrier gas for the GC/MS, at a constant flow of $1.2 \mathrm{~mL} \cdot \mathrm{min}^{-1}$ (constant flow mode) and hydrogen for the GC-FID at $1.5 \mathrm{~mL} \cdot \mathrm{min}^{-1}$ (constant pressure mode). The injection was performed under splitless conditions $(0.5 \mathrm{~min})$ with the injector at $250{ }^{\circ} \mathrm{C}$. The mass spectrometer was used in the mode of Electron Ionization (EI), with ionization energy of $70 \mathrm{eV}$, operated under full scan with an $\mathrm{m} / \mathrm{z}$ acquisition range of 40 to 300 . The GC interface and source temperature were set to $250{ }^{\circ} \mathrm{C}$. GC/MS data were acquired and treated by Thermo Finnigan Xcalibur and Waters-Micromass MassLynx software packages. Compounds were identified by their characteristic fragmentation patterns in combination with authentic reference compounds and tentatively assigned using the NIST98 Library and Adams (2001) retention indices database. Nine volatile samples were collected from pine plants subjected to drought stress and 10 samples from well watered pines, prior the choice tests were performed. Volatiles were collected in January 2008, a few days before the host preference trials were performed. For each tree sampled, average values were obtained from two samples of the volatiles taken at ca. $3 \mathrm{~h}$ intervals, between 9.00 and 17.00, corresponding to the period of the day of higher monoterpene emissions (Holzke et al., 2006). Plants from drought stressed and well watered groups were equally sampled, throughout the day.

\subsection{Statistical analysis}

A generalized linear model (GLM) was used to test for the effects of the plant treatments, years and interactions with both the number of entry holes and the number of successful tunnels. The dependent variables were assumed to follow a Poisson distribution, as evidenced by a Kolmogorov-Smirnov test, a log link function being considered. Differences between treatments for the final needle $\psi$, monoterpenes concentrations and length of the tunnels were tested by independent sample Student's $t$-test. Beetle mortality between treatments, both for no-choice and two-choice tests, was compared by paired sample Student's $t$-test, using each one of the four separate tests as a pair $(n=4)$.

Two-way ANOVA was used to test for differences in the beetles fat content, between plant treatment groups and years. Homoscedascity of variances was analyzed by Levene's test and adjustment to the normal and Poisson distributions by Kolmogorov-Smirnov's test. A discriminant analysis was applied, based on a stepwise variable selection procedure, to predict plant group membership according to the composition in monoterpenes of the plants sampled.

\section{RESULTS}

\subsection{Predawn needle water potential}

The final predawn needle $\psi$ minimum and maximum values observed ranged, over the three years, from -0.20 


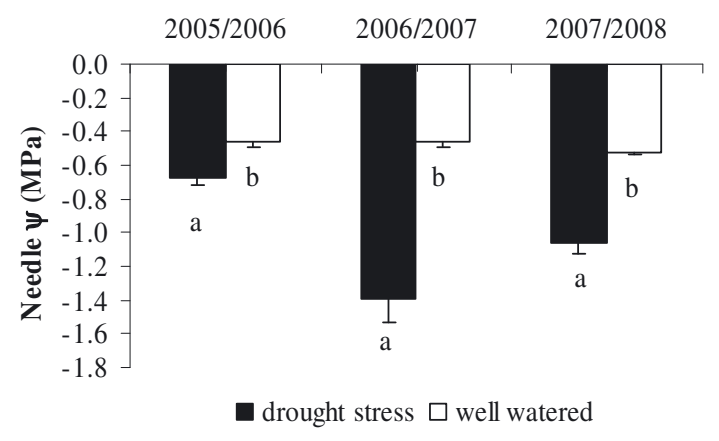

Figure 1. Predawn needle water potential (mean -SE) of $P$. pinaster needles, measured in December/January, $2005(n=11), 2006(n=$ $36)$ and $2007(n=71)$, before tests. Within each year, bars caped with different letters differ significantly at $p<0.05$.

to $-0.70 \mathrm{MPa}$ in well watered plants and from -0.53 to $-2.10 \mathrm{MPa}$ in drought stressed plants. Needle $\psi$ differed significantly between drought stressed and non stressed plants, in all years: $t_{9}=-3.940, p=0.003 ; t_{15.7}=-6.577, p<0.001$; $t_{40.6}=-8.780 ; p<0.001$, respectively for 2005, 2006 and 2007 (Fig. 1).

\subsection{Beetles preference and performance}

In no-choice tests, neither the number of entry holes, nor the number of tunnels excavated, differed significantly between tree treatments $\left(\chi_{1}^{2}=0.170 ; p=0.680\right.$ and $\chi_{1}^{2}=1.508$, $p=0.219$, respectively) (Fig. 2). The ratio between the number of tunnels excavated and of entry holes was 0.69 for drought stressed, and 0.80 for well watered plants.

In paired-choice tests, both the number of entry holes and of tunnels, were significantly higher in well watered plants than in stressed ones $\left(\chi_{1}^{2}=8.008 ; p=0.005\right.$ and $\chi_{1}^{2}=10.344$, $p=0.001$, respectively) (Fig. 2). No significant interactions were uncovered for either the number of tunnels, or of entry holes, between years and treatments.

Beetle mortality was significantly higher in drought stressed plants than on well watered ones $\left(t_{3}=6.845, p=\right.$ 0.006) (Fig. 3).

Higher fat contents were observed in beetles fed on well watered, than on stressed plants $\left(F_{1,29}=3.053, p=0.09\right)$, (Fig. 4). Significantly higher fat contents were observed in 2007, when beetles were allowed to feed for a longer period, than in $2006\left(F_{1,29}=12.278, p=0.002\right)$. No interaction was found between years and tree treatments $\left(F_{1,29}=0.0428\right.$, $p=0.839)$. Shoot tunnel mean length did not differ significantly between well watered plants $(2.096 \mathrm{~cm} \pm 0.207, n=29)$, and stressed plants $(2.077 \mathrm{~cm} \pm 0.211, n=49)$.

\subsection{Volatiles}

Twenty four chromatographic peaks were identified using GC/MS, linear retention indices and standard co-injection:
(Z)-3-hexen-1-ol, dimethylbenzene, tricyclene, thujene, $\alpha$ pinene, camphene, $\beta$-pinene, myrcene, $\Delta-2$ carene, hexenol acetate, $\alpha$-phellandrene, hexenyl acetate, $\Delta-3$ carene, $\alpha$ terpinene, $\rho$-cymene, limonene, $\beta$-phellandrene, cis-ocimene, trans-ocimene, $\gamma$-terpinene, $\alpha$-terpinolene, alloocimene, $\beta$ caryophyllene and germacrene $\mathrm{D}$.

Four main monoterpenes were responsible, on average, for $90 \%$ of the volatiles emitted by P. pinaster plants: myrcene, limonene, $\beta$-pinene and $\alpha$-pinene. The following major compounds were germacrene $\mathrm{D}$ and $\beta$-caryophyllene, with a total contribution of about 3\%. All other compounds contributed, on average with less than $0.6 \%$ to the emissions, drifting around the detection threshold.

Plants subjected to drought stress emitted significantly more myrcene than well watered ones $\left(t_{17}=3.737, p=\right.$ $0.002)$, and less $\beta$-pinene $\left(t_{17}=-4.622 ; p<0.001\right)$ (Fig. 5). Regarding $\alpha$-pinene and limonene, no significant differences were detected between treatments. A negative correlation was found between the relative contents of myrcene and leaf $\psi$ $(r=-0.747, p=0.054, n=7)$, and a positive one between $\beta$-pinene and leaf $\psi(r=0.870, p=0.011, n=7)$. Concomitantly, a negative correlation was found between myrcene and $\beta$-pinene $(r=-0.733, p<0.001, n=19)$. No differences between treatments were detected regarding other compounds.

Drought stressed pines could be discriminated according to volatile emissions from well watered ones. $\beta$-pinene was the variable with the highest discriminant ability $\left(F_{1,18}=13.118\right.$, $p=0.002$ ) and also the sole variable needed to predict group membership. Overall, $89.5 \%$ of the original cases grouped were correctly classified by the model.

\section{DISCUSSION}

Present findings show that host selection and performance by $T$. destruens during the shoot feeding phase, were affected by drought stress induced to $P$. pinaster plants.

Concerning host selection, it was demonstrated that in paired-choice tests, $T$. destruens preferred vigorous plants to water stressed ones. However, when no alternative well watered hosts were available, drought stress did not significantly influence the number of shoot attacks. This result is consistent with previous observations, for higher levels of shoot infestation by Tomicus spp. in vigorous trees (Långström et al., 2002). Yet, since pine shoot beetles prefer debilitated trees for trunk attack (Schröeder, 1987), present findings indicate that different mechanisms are involved in the host selection process, during the two distinct life- cycle phases.

Tomicus spp. host selection and trunk attack are guided by responses to host volatiles, particularly monoterpenes (Vité et al., 1986). This work addressed host olfactory recognition during the shoot feeding phase, uncovering that pine plants can be discriminated according to their physiological status, based upon the relative composition of volatile emissions, since well watered plants emitted higher percentages of $\beta$-pinene and lower percentages of myrcene, than stressed 


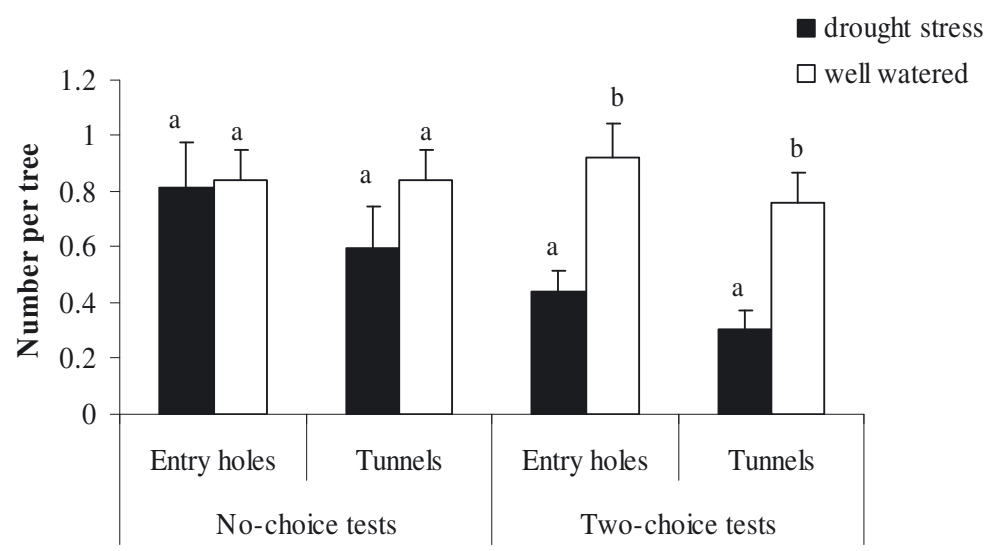

Figure 2. Number of entry holes, and of successful shoot tunnels (mean $+\mathrm{SE}$ ) excavated by $T$. destruens in P. pinaster trees subjected to two treatments, drought stress and well watered, observed in no-choice $(n=32)$ and paired-choice tests $(n=66)$. Within each year, bars caped with different letters differ significantly at $p<0.05$.

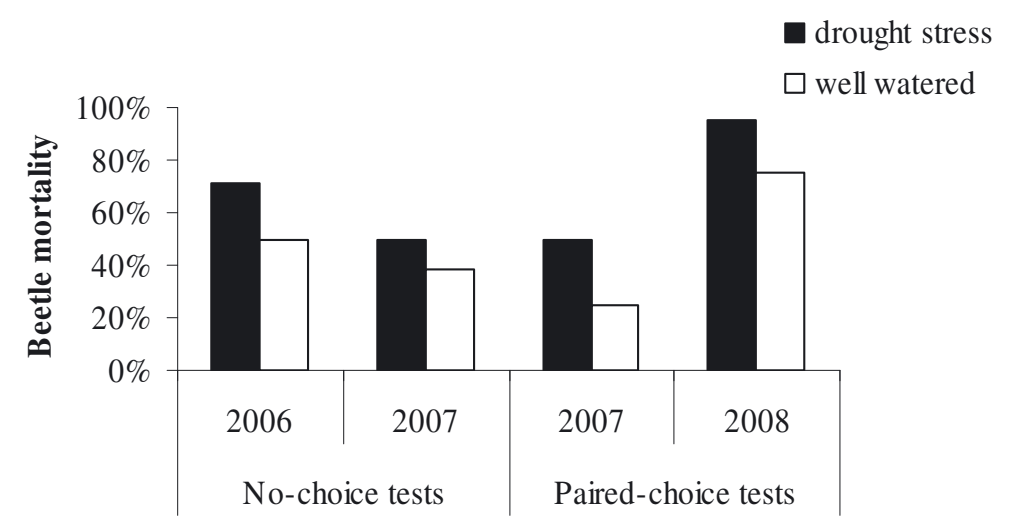

Figure 3. T. destruens mortality in the shoot-feeding phase, in P. pinaster trees subjected to two treatments, drought stressed and well watered, observed in no-choice and paired-choice tests.

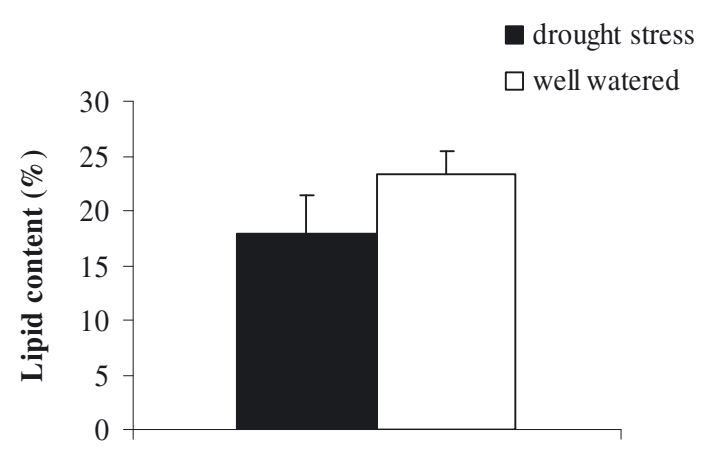

Figure 4. Fat content (mean $\%$ of dry weight $+\mathrm{SE}$ ) of $T$. destruens in $P$. pinaster drought stressed and well watered trees, in two experimental seasons, 2005/2006 ( $n=3$ and 6, respectively) after 15 days of shoot feeding, and 2006/2007 ( $n=9$ and 15, respectively), after 28 days of shoot feeding.

ones. Results agree with Ormeño et al. (2007) who related Pinus halepensis Miller water stress status to differences in VOCs emissions.

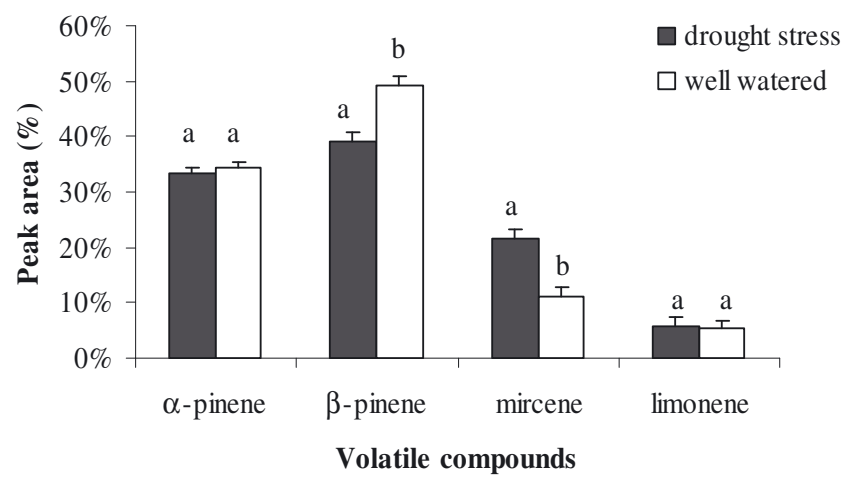

Figure 5. Main volatile compounds emitted by $P$. pinaster young potted trees, subjected to two treatments, drought stress or well watered. January 2008. Bars caped with different letters differ significantly at $p<0.05$.

$\beta$-pinene was the compound emitted in higher percentages, in agreement with previously determined terpene profiles for $P$. pinaster needles (Kleinhentz et al, 1999; Paiva et al., 
in press) and the sole variable needed in a stepwise discriminant analysis, to explain the differences between treatment groups. Such result reflects the significant negative correlation detected between $\beta$-pinene and myrcene, indicating that under drought stress, an interchange between both compounds may take place, along the kinetic pathway of terpenes, in response to tree physiological state. This hypothesis is supported by observations in $P$. pinaster, where the acyclic monoterpenes myrcene and trans- $\beta$-ocimene act as transitory compounds before the biosynthesis of the cyclic monoterpenes $\alpha$ - and $\beta$ pinene, all being accumulated in the same resin ducts of the needles (Gleizes et al., 1982).

Using EAG-GC, Faccoli et al. (2008) detected antennal activity of callow $T$. destruens to $P$. pinea bark and shoot volatiles, in the chromatogram region corresponding to myrcene, whereas no antennal response to $\beta$-pinene was recorded. Insect electrophysiological responses specificity depend on a number of variables, such as stimulus dose (Larsson et al., 2001), whereas both $P$. pinea needles and bark, emit very low amounts of $\beta$-pinene (Paiva et al., in press; Santos et al., 2006). Furthermore, electrophysiological recordings performed under laboratory conditions and insect field behaviour might not have an exact correspondence (e.g. Andersson et al., 2009).

Results showed that higher T. destruens mortality was observed upon water-stressed plants, than on well watered ones which, accordingly, were preferentially selected by adult beetles. However, the defensive role of pine oleoresins against bark beetles has been widely recognized (e.g. Lombardero et al., 2000), while drought stress is known to reduce resin flows, resulting in improved host suitability (Lorio et al., 1995). In fact, both constitutive and inducible defences may vary in response to stress (Lombardero et al., 2000), while the former can increase under moderate drought stress, as a result of slower growth leading to a surplus of carbon storage allocated to secondary metabolites (Herms and Mattson, 1992). In parallel, dehydration leads to starch breakdown increasing the concentration of low molecular weight compounds (Chaves, 1991), which may also be allocated to defence metabolites.

Effectively, in drought stressed $P$. pinaster trees (needle $\psi=-1.5 \mathrm{MPa})$ an increase of hexoses (fructose + glucose) was observed (Picon-Cochard and Guehl, 1999). Furthermore, an efficient osmotic adjustment, resulting from the accumulation of low molecular weight compounds, occurred in $P$. pinaster under drought (Nguyen-Queyrens et al., 2002). The needle $\psi s$ of drought stressed plants varied, on average, between -0.68 and $-1.39 \mathrm{MPa}$, values which are significantly lower than those of well watered plants and characteristic for moderately water stressed $P$. pinaster (Nguyen-Queyrens et al., 2002; Picon-Cochard and Guehl, 1999). Further studies are needed to clarify the relationship between high levels of constitutive defences and moderate drought stress.

Adult shoot feeding is essential for the completion of Tomicus spp. reproductive maturation, while also influencing the beetles fat contents (Fernandez Fernandéz et al., 1999), flying capacity, reproductive performance, survival, dispersion and host colonization (Anderbrant, 1988; Fernandez Fernandéz et al., 1999). Although a tendency for higher fat accumula- tion in beetles fed on well watered plants, by comparison with stressed ones was observed, results had only borderline statistical significance $(p=0.09)$.

\section{CONCLUSIONS}

In the shoot feeding phase and when one host species only was available, $T$. destruens adults discriminated and actively selected plants according to their physiological condition, preferentially colonizing vigorous trees. In accordance, a higher performance was achieved upon non-stressed hosts.

Well watered $P$. pinaster plants emitted higher percentages of $\beta$-pinene and lower percentages of myrcene, than stressed ones, indicating that the colonization process may be guided by monoterpene emissions. It can thus be inferred that, whenever abundant host breeding material becomes available such as after thinning, or the occurrence of forest fires, and vigorous pine stands remain in the vicinity, outbreaks of $T$. destruens will be favoured.

Finally, T. destruens ecology and colonization behaviour appear as the outcome of a successful adaptation process to Mediterranean climatic conditions. In fact, the beetles mainly feed on shoots during the spring, prior to the occurrence of droughts, when high energetic inputs are required for oocyte maturation. Trunk attack follows after the summer drought season, thus providing the offspring with suitable breeding material.

Acknowledgements: We thank Mrs. Maria João Barrento for assistance with laboratory work and Dr. Teresa Vasconcelos, Polytechnic Institute of Coimbra, for help with the collection of attacked logs. This study was financed by Fundação para a Ciência e Tecnologia, FCT-MCES, Portugal, project POCTI/AGG/47275/2002, with partial support from the European Regional Development Fund.

\section{REFERENCES}

Adams R.P., 2001. Identification of essential oil components by gas chromatography quadrupole mass spectroscopy. Allured Pub Corp. Allured, Illinois, $455 \mathrm{p}$.

Almquist A.C., Faldt J., Yart A., Chevet Y., Sauvard D., Lieutier F., and Borg-Karlson A.K., 2006. Host-selection in Tomicus piniperda L.: Composition of monoterpene hydrocarbons in relation to attack frequency in the shoot feeding phase. Zeit. Naturforsch. C 61:439-44.

Anderbrandt O., 1988. Survival of parent and brood adult bark beetles, Ips typographus, in relation to size, lipid content and re-emergence or emergence day. Physiol. Entomol. 13: 121-129.

Andersson M.N., Larsson M.C., and Schlyter F., 2009. Specificity and redundancy in the olfactory system of the bark beetle Ips typographus: Single-cell responses to ecologically relevant odors. J. Inst. Phys. 55: 556-567.

Chaves M.M., 1991. Effects of water deficits on carbon assimilation. J. Exp. Botany 42:1-16.

Faccoli M., Anfora G., and Tasin M., 2008. Responses of the mediterranean pine shoot beetle Tomicus destruens (Wollaston) to pine shoot and bark volatiles. J. Chem. Ecol. 34: 1162-1169.

Faccoli M., Battisti A., and Masutti L., 2005. Phenology of Tomicus destruens (Wollaston) in northern Italian pine stands. Lieutier F. and Ghaioule D. (Eds), Entomological research in Mediterranean forest ecosystems. INRA Editions, Paris: 185-193. 
Fernandez Fernandéz M.M., Salgado Costas J.M., and Pajares Alonso J.A., 1999. The seasonal development of the gonads and fat content of Tomicus minor (Coleoptera, Scolytidae) [lesser pine shoot beetle]. Belg. J. Entomol. 1: 311-324.

Gleizes M., Marpeau A., Pauly G., and Bernard-Dagan C., 1982. Role of acyclic compounds in monoterpene biosynthesis in Pinus pinaster. Phytochemistry 21: 2641-2644.

Grégoire J.-C. and Evans H.F., 2004. Damage and control of bawbilt organisms an overview. In: Lieutier F., Day K.R., Battisti A., Grégoire J.-C., and Evans H.F. (Eds). Bark and wood boring insects in living trees in Europe, a synthesis. pp. 19-37.

Haack R.A., Lawrence R.K., and Heaton G.C., 2001. Tomicus piniperda (Coleoptera: Scolytidae) shoot-feeding characteristics and overwintering behavior in scotch pine christmas trees. J. Econ. Entomol. 94: 422-429.

Herms D.A. and Mattson W.J., 1992. The dilemma of plants: to grow or defend. Quart. Rev. Biol. 67: 283-335.

Holzke C., Hoffmann T., Jaeger L., Koppmann R., and Zimmer W., 2006. Diurnal and seasonal variation of monoterpene and sesquiterpene emissions from Scots pine (Pinus sylvestris L.). Atmos. Environ. 40: 3174-3185.

Kleinhentz M., Jactel H., and Menassieu P., 1999. Terpene attractant candidates of Dioryctria sylvestrella in maritime pine (Pinus pinaster) oleoresin, needles, liber, and headspace samples. J. Chem. Ecol. 25: 2741-2756.

Koricheva J., Larsson S., and Haukioja E., 1998. Insect performance on experimentally stressed woody plants. Annu. Rev. Entomol. 43: 195216.

Långström B., Lisha L., Hongpin L., Peng C., Haoran L., Hellqvist C., and Lieutier F., 2002. Shoot feeding ecology of Tomicus piniperda and T. minor (Col., Scolytidae) in southern China. J. Appl. Entomol. 126: $333-342$.

Larsson M.C., Leal W.S., and Hansson B.S., 2001. Olfactory receptor neurons detecting plant odours and male volatiles in Anomala cuprea beetles (Coleoptera: Scarabaeidae). J. Inst. Phys. 47: 1065-1076.

Lieutier F., Ye H., and Yart A., 2003. Shoot damage by Tomicus sp (Coleoptera: Scolytidae) and effect on Pinus yunnanensis resistance to subsequent reproductive attacks in the stem. Agr. For. Entomol. 5: 227-233.
Lombardero M.J., Ayres M.P., Lorio P.L. Jr., and Ruel J.J., 2000. Environmental effects on constitutive and inducible resin defences of Pinus taeda. Ecol. Lett. 3: 329-339.

Lorio P.L. Jr., Stephen F.M., and Paine T.D., 1995. Environment and ontogeny modify loblolly pine response to induced acute water deficits and bark beetle attack. For. Ecol. Manage. 73: 97-110.

Mattson W.J. Jr. and Haack R.A., 1987. The role of drought in outbreak of plant-eating insects. Bioscience 37: 110-118.

Mendel Z., 1987. Major pests of man-made forests in Israel: origin, biology, damage and control. Phytoparasitica. 15: 131-137.

Nguyen-Queyrens A., Costa P., Loustau D., and Plomion C., 2002. Osmotic adjustment in Pinus pinaster cuttings in response to a soil drying cycle. Ann. For. Sci. 59: 795-799.

Ormeño E., Mévy J.P., Vila B., Bousquet-Mélou A., Greff S., Bonin G., and Fernandez C., 2007. Water deficit stress induces different monoterpene and sesquiterpene emission changes in Mediterranean species. Relationship between terpene emissions and plant water potential. Chemosphere. 67: 276-284.

Paiva M.R., Mateus E., Santos M.H., and Branco M.R., 2010. Pine volatiles mediate host selection for oviposition by Thaumetopoea pityocampa (Lep., Notodontidae). J. Appl. Ent. (in press).

Picon-Cochard C. and Guehl J.M., 1999. Leaf gas exchange and carbohydrate concentrations in Pinus pinaster plants subjected to elevated $\mathrm{CO}_{2}$ and a soil drying cycle. Ann. For. Sci. 56: 71-76.

Santos A.M., Vasconcelos T., Mateus E., Farrall M.H., Gomes da Silva M.D.R., Paiva M.R., and Branco M.R., 2006. Characterization of the volatile fraction emitted by phloems of four Pinus species by solidphase microextraction and gas chromatography-mass spectrometry. J. Chromat. A. 1105: 191-198.

Schröeder L.M., 1987. Attraction of the bark beetle Tomicus piniperda to Scots pine trees in relation to tree vigor and attack density. Entomol. Exp. Appl. 44: 53-58.

Vasconcelos T., Horn A., Lieutier F., Branco M., and Kerdelhué C., 2006. Distribution and population genetic structure of the Mediterranean pine shoot beetle Tomicus destruens in the Iberian Peninsula and Southern France. Agr. For. Entomol. 8: 103-111.

Vité J.P., Volz H.-A., Paiva M.R., and Bakke A., 1986. Semiochemicals in host selection and colonization of pine trees by the pine shoot beetle Tomicus piniperda. Naturwissenschaften 73: 39-40. 